\title{
INTRACELLULAR DIVALENT CATIONS AND PLATEAU DURATION OF SQUID GIANT AXONS TREATED WITH TETRAETHYLAMMONIUM
}

\author{
Susumu Terakawa, Misako Nagano, and Akira Watanabe \\ Department of Physiology, Faculty of Medicine, Tokyo Medical \\ and Dental University, Yushima, Bunkyo-ku, Tokyo, 113 Japan
}

\begin{abstract}
Squid giant axons were intracellularly perfused with a solution containing $100 \mathrm{~mm} \mathrm{~K} \mathrm{~K}^{+}$and $5 \mathrm{~mm}$ tetraethylammonium (TEA) to obtain action potentials with a long-lasting plateau. Effects of intracellular divalent cations on the plateau of the action potentials were examined by introducing 0.1-10 $\mathrm{mM} \mathrm{Ca}^{2+}, \mathrm{Sr}^{2+}, \mathrm{Mg}^{2+}, \mathrm{Ba}^{2+}$, or $\mathrm{Mn}^{2+}$ into the perfusate under these conditions. $\mathrm{Ca}^{2+}, \mathrm{Sr}^{2+}$ and $\mathrm{Mn}^{2+}$ were found to shorten the plateau duration drastically. Upon removal of the divalent cations in the perfusate, there was a recovery in the plateau duration. The recovery was imperfect in the case of $\mathrm{Ca}^{2+}$, nearly perfect in the case of $\mathrm{Sr}^{2+}$, and perfect in the case of $\mathrm{Mn}^{2+}$. Voltage-clamp experiments carried out on axons intracellularly perfused with the control (i.e., divalent cation free) perfusate revealed the existence of a late inward current through the membrane. Intracellularly administered $\mathrm{Mn}^{2+}$ (1-3 mM) blocked this late inward current and decreased the membrane conductance during the late period of voltage clamping. Intracellular $\mathrm{Mg}^{2+}(1-10 \mathrm{mM})$ prolonged the action potential plateau produced by TEA reversibly in some axons; however, this effect was masked by an opposing (i.e., irreversibly plateau-shortening) effect in most axons. $\mathrm{Ba}^{2+}$ applied intracellularly prolonged the action potential duration regardless of the presence or absence of TEA in the perfusate. We emphasize that the effects of divalent cations applied internally are very similar to those observed when these cations are applied externally, except that the effective concentration is far lower in the case of internal application. It is suggested that the primary site of action of divalent cations might be on or near the internal surface of the axonal membrane.
\end{abstract}

In 1968, Tasaki presented a theoretical argument that the excited state of the axonal membrane is terminated because of an increase in the concentration

Received for publication September 27, 1977

寺川 進, 長野及さ子, 渡辺 昭 
of interdiffusing ions which accumulate near the membrane to form stagnant layers. He regarded the intracellular accumulation of $\mathrm{Ca}^{2+}$ to be most crucial. However, at that time there was no experimental evidence to support this hypothesis. Intracellular injection of $\mathrm{Ca}^{2+}$ either did not produce any pronounced effect on the action potential of squid gaint axons (BEGENISICH and LYNCH, 1974), or if any, a slight prolongation of the duration together with a decrease in amplitude and in rate of rise (TASAKI et al., 1967; YAMAGISHI, 1977). However, a recent experiment by ISENBERG (1975) indicated that the intracellular $\mathrm{Ca}^{2+}$ shortens the plateau duration of the action potential of cardiac Purkinje fibers. The effect was ascribed to an increased potassium conductance which is observed in the resting membrane of several invertebrate and vertebrate neurons (MEECH, 1972; KRNJEVIĆ and Lisiewicz, 1972; MeEch, 1974a, b). It is possible, therefore, that the effect of $\mathrm{Ca}^{2+}$ on the plateau potential in squid axons is also large enough to draw conclusions without ambiguity, even though the effect on the natural brief action potential is not clear.

In the present paper, we report that intracellularly administered $\mathrm{Ca}^{2+}, \mathrm{Sr}^{2+}$ and $\mathrm{Mn}^{2+}$ markedly shorten the duration of the action potential plateau in tetraethylammonium (TEA)-treated squid giant axons. A voltage clamp study revealed that a major effect of intracellular $\mathrm{Mn}^{2+}$ is to reduce or eliminate the late inward current observed when TEA-treated axons are clamped with a depolarizing voltage pulse.

\section{METHODS}

Freshly excised giant axons of squid, Dorytheusis bleekeri, (400-625 $\mu \mathrm{m}$ in diameter) were used. All experiments were done from axons mounted horizontally in the Lucite chamber which contained artificial sea water. We used the double cannulation technique for the intracellular perfusion (WATANABE and TASAKI, 1972). The length of the perfused zone was usually $13-17 \mathrm{~mm}$. At the initial stage of perfusion we used a solution containing protease (Protease Type VII, Sigma P5255, $0.1 \mathrm{mg} / \mathrm{ml}$ ) for 2-4 min to remove the major portion of axoplasm.

The membrane potential was recorded with an axially inserted glass capillary electrode $(80 \mu \mathrm{m}$ in diameter) filled with $0.6 \mathrm{M}$ or $3 \mathrm{M} \mathrm{KCl}$-agar; the tip of the electrode was placed at approximately the midpoint of the perfused zone. Electrical stimuli were delivered either through an internal electrode made of platinized platinum wire (50 $\mu \mathrm{m}$ in diameter), or through a pair of platinum electrodes placed externally at one end of the axon. In voltage clamp experiments we employed the technique described by MOORE (1971).

Since intracellularly administered $\mathrm{Ca}^{2+}$ usually produces a detrimental effect of the excitability of squid giant axons, rapid replacement of the internal solution was found essential in order to obtain reversible results. For this purpose we modified the perfusion system to reduce the dead space and employed several solenoid valves to facilitate rapid exchange of solutions (see Fig. 1). The desired 


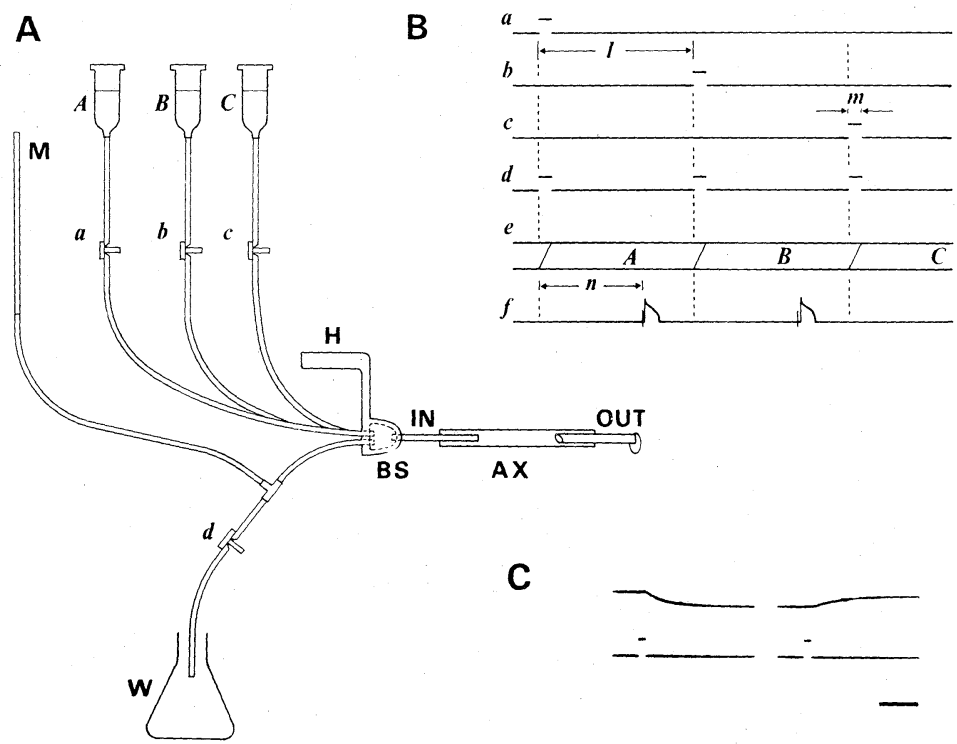

Fig. 1. The experimental set-up for the intracellular perfusion which allowed a rapid exchange of internal perfusates. A, a schematic representation of the system. AX, giant axon. IN, inlet pipette for the perfusate. OUT, outlet pipette for the perfusate. $\mathrm{BS}$, a compartment of about $10 \mu 1$ volume at the base of the inlet pipette. $\mathrm{H}$, the holder of the inlet pipette and its base compartment, mounted on a micromanipulator. $A, B$ and $C$, reservoirs for perfusates; $a, b, c$ and $d$, electric valves which usually close the tubings from the respective reservoirs and the waste to the base compartment. W, an Erlenmeyer flask to receive waste perfusate. $\mathrm{M}$, a branch of tubing which opens at the top end. $\mathrm{B}$, time sequence for valve operation and stimulation; $a, b, c$ and $d$ indicate timing of pulses which open the respective electric valves shown in $\mathrm{A} ; e$ indicates periods during which one of the perfusates shown in A flows; $f$ indicates timing of stimulation with the resultant action potentials; $l$, the basic repeating period; $m$, the period of opening of valves; $n$, the period between opening of a valve and delivery of a stimulus. $\mathrm{C}$, upper traces show changes of transmitted light through the central portion of the perfused zone. Lower traces show the timing of application of electric pulses which drove the valves. The perfusing fluid was switched from a transparent solution to a dyed solution (left), and was switched back to the transparent solution again (right). Time: $10 \mathrm{~s}$.

perfusate was selected by an opening of the proper valve. During perfusion with one solution, all four valves $(a, b, c$, and $d)$ in Fig. 1 were closed and the hydrostatic pressure applied to the perfusate was maintained by the level of the surface of the solution in tubing $M$ which was open at its upper end. When rapid exchange of solutions was required, two valves, one of the three reservoir valves $(a, b$ or $c$ ) and the waste valve $(d)$, were opened simultaneously. When these two valves were open, the perfusate flowed rapidly from one of the reservoirs $(A, B$ or $C$ ) to the waste (W). The flow washed away the content of the small compartment (BS) at the base of the inlet pipette and replaced it with the new perfusate. 
The volume of compartment BS was about $10 \mu \mathrm{l}$. This compartment was usually rinsed with $200 \mu \mathrm{l}$ of new perfusate. The amount of the perfusate required for rinsing was controlled by the length of the valve opening time (usually $2 \mathrm{~s}$ ) and by the hydrostatic pressure difference between reservoirs and the waste. The height of the reservoirs and of the waste were adjusted in such a way that the fluid level in the tubing $M$ did not change appreciably during the valve operation. We could not measure pressure changes which might be generated inside the axon during the valve operation accurately; no change in the axon diameter was detected under a dissection microscope (see Fig. 2). The axon was never excited by the valve operation.

The rate of exchange of the fluid was estimated by the use of a dyed perfusate. When the optical density of the axon was measured through a photodiode in the middle portion of the perfused zone (see Fig. 1C), a change in transmitted light intensity could be detected within $2 \mathrm{~s}$ after opening the valves and a steady state was reached within about $20 \mathrm{~s}$. The actual exchange process of the internal perfusate was further examined by the use of $16 \mathrm{~mm}$ movie (see Fig. 2). A new dyed perfusate is seen to emerge from the inlet pipette within a fraction of a second and to enter the outlet pipette within 2 or $3 \mathrm{~s}$. The axon was filled with the new perfusate almost completely within $10 \mathrm{~s}$. However, the density of the color at the edge of the axon continued to increase during another period of $10 \mathrm{~s}$. In most experiments the valves were operated periodically at $30 \mathrm{~s}$ interval, in order to prevent contamination of the perfusate by the ingredients in other tubings which have openings to the compartment.

It is known that the excitability of a perfused axon can be maintained for a long period of time when the internal perfusate contains fluoride or phosphate as the major anion (TASAKI et al., 1965). We therefore used a solution containing $90 \mathrm{~mm} \mathrm{KF}, 10 \mathrm{mM} \mathrm{K} \mathrm{K}^{+}$(as phosphate salts) and $5 \mathrm{~mm} \mathrm{TEA-Cl}$ as a standard perfusate to maintain the excitability. Divalent cations, $\mathrm{Ca}^{2+}, \mathrm{Sr}^{2+}$ and $\mathrm{Mg}^{2+}$ are known to combine with fluoride and to cause precipitation. Before testing the effects of $\mathrm{Ca}^{2+}, \mathrm{Sr}^{2+}$ and $\mathrm{Mg}^{2+}$, therefore, we replaced the standard perfusate with a control perfusate, which usually contained $100 \mathrm{~mm} \mathrm{~K}$-glutamate and $5 \mathrm{~mm}$ TEA-Cl. $\mathrm{BaF}_{2}$ is soluble in water, its solubility product being $1.7 \times 10^{-6} \mathrm{M}^{3}$. In experiments with $\mathrm{Ba}^{2+}$, we therefore used, as the control perfusate, a solution containing $25 \mathrm{~mm} \mathrm{KF}$ and $5 \mathrm{~mm}$ TEA-Cl. $\mathrm{MnF}_{2}$ is also soluble in water; in experiments with $\mathrm{Mn}^{2+}$, we used a solution containing $100 \mathrm{mM} \mathrm{KF}$ and $5 \mathrm{mM}$ TEA-Cl as the control perfusate. We often added $0.1 \mathrm{~mm}$ EDTA to the control perfusates in order to ensure the maintenance of low internal divalent cation concentration. However we did not find any detectable effect of eliminating EDTA from the control solutions. The tonicity of the solution was adjusted with glycerol. The $\mathrm{pH}$ of the internal perfusate was kept at $7.3 \pm 0.1$ by addition of Tris-glutamate or potassium phosphate buffer.

In typical experiments we switched the intracellular solution successively 


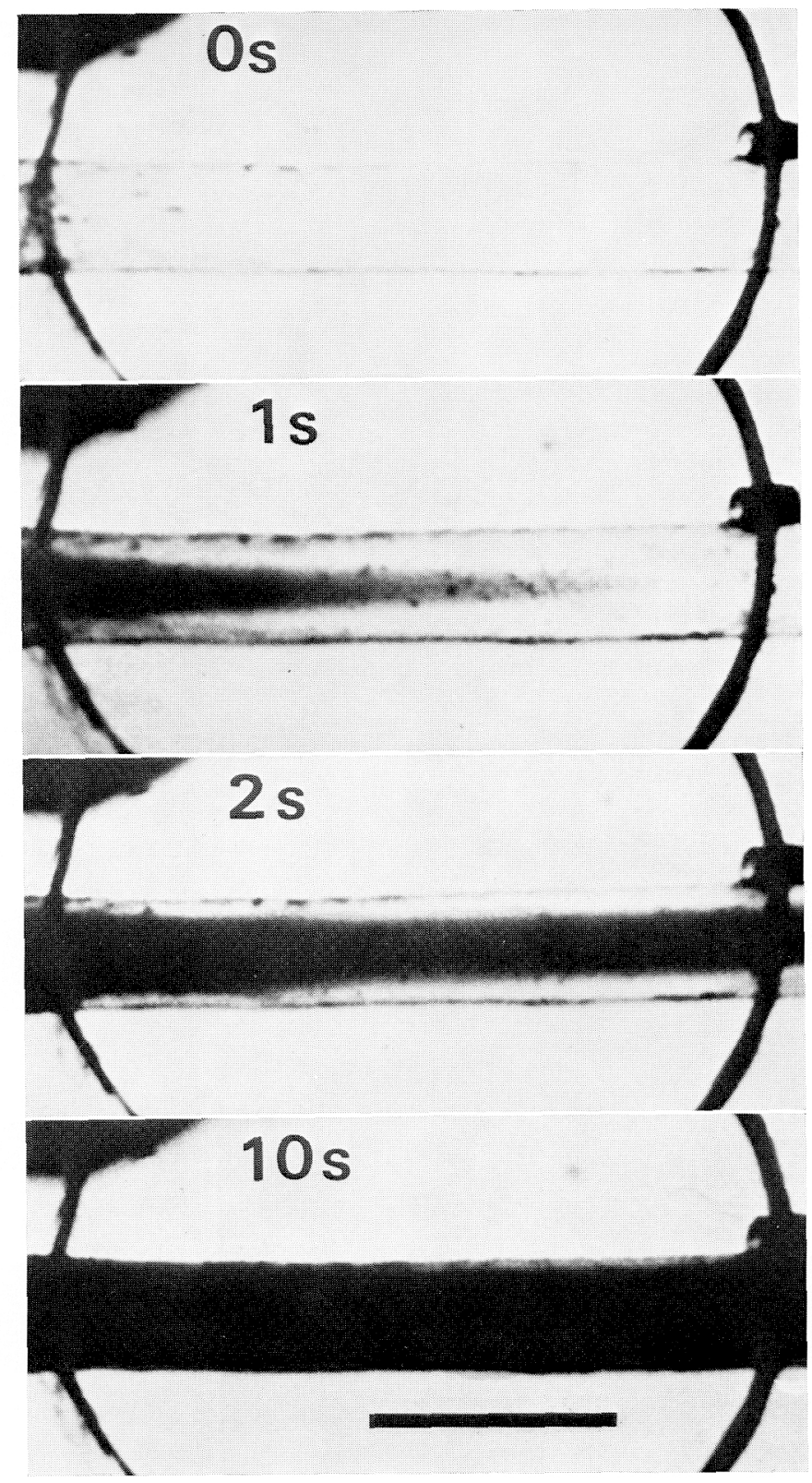

Fig. 2. Photomicrographic pictures of a perfused squid giant axon during the exchange of intracellular perfusates. The pictures were selected from a $16 \mathrm{~mm}$ movie film driven at a rate of 24 frames per second. The valves opened at $0 \mathrm{~s}$ and closed at about $2 \mathrm{~s}$. The new perfusate was dyed deeply with chlorphenol red. The thick curved lines are edges of a window made at the bottom of the lucite chamber for optical measurements. The bar at the bottom right indicates $1 \mathrm{~mm}$. 
in the order of the standard, control, test, control, and standard perfusates. The period of application of the control or the test perfusate was within 2 min (see Figs. 4 and 6).

In most experiments artificial sea water was used as the external medium which contained the following concentrations (expressed in $\mathrm{mM}$ ) of salts: $450 \mathrm{NaCl}$, $10 \mathrm{KCl}, 50 \mathrm{CaCl}_{2}, 10 \mathrm{MgCl}_{2}$; its $\mathrm{pH}$ was adjusted by $1 \mathrm{~mm}$ Tris- $\mathrm{HCl}$ buffer to a value of $8.0-8.2$.

We kept the following parameters approximately constant during one experiment: the stimulus frequency usually at a rate of once in $30 \mathrm{~s}$, the interval between valve operation and stimulation usually at about $20 \mathrm{~s}$ (see Fig. 1B), the room temperature at $20 \pm 1{ }^{\circ} \mathrm{C}$, and the hydrostatic pressure on the intracellular perfusate at $28 \pm 3 \mathrm{~cm} \mathrm{H}_{2} \mathrm{O}$.

\section{RESULTS}

\section{Effects of intracellular $\mathrm{Ca}^{2+}$}

Figure 3 shows the typical result of an experiment of intracellular perfusion with $\mathrm{Ca}^{2+}$. Replacement of the TEA-free perfusate with the standard TEAcontaining perfusate converted the action potential from a brief spike to one followed by a plateau with a duration of several seconds. We often observed a burst of spikes during the plateau phase (Fig. 3-1). A subsequent switching of the perfusate from the standard to the control often prolonged the plateau duration transiently (Fig. 3-2), then shortened it gradually. It was usually difficult to

1
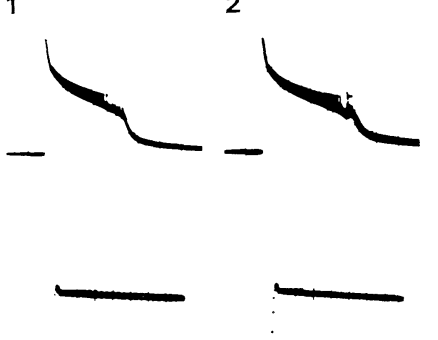

3

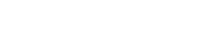

4

5

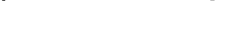

5
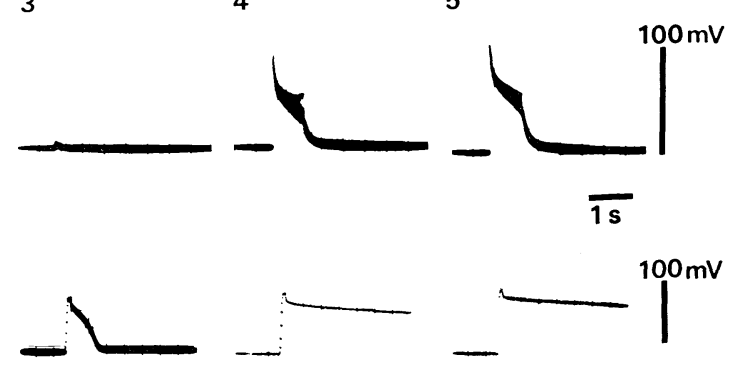

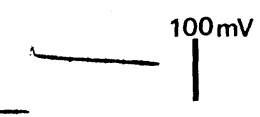

$\overline{20 \mathrm{~ms}}$

Fig. 3. Effects of $0.3 \mathrm{mM} \mathrm{Ca}^{2+}$ on the plateau of TEA-treated axon. Top traces show the whole action potentials on a slow time base. Bottom traces show only the initial part of the action potentials on a rapid time base. 1: records taken with the standard perfusate as the intracellular solution. 2: records taken $50 \mathrm{~s}$ after switching to the control perfusate which contained (in mM) $100 \mathrm{~K}$-glutamate, 5 TEA-Cl, $0.1 \mathrm{~K}$-EDTA and 2 Trisglutamate. 3: records taken $50 \mathrm{~s}$ after switching to the test perfusate which contained $100 \mathrm{~K}$-glutamate, $5 \mathrm{TEA}-\mathrm{Cl}, 0.3 \mathrm{CaCl}_{2}$ and 2 Tris-glutamate. 4 : records taken $50 \mathrm{~s}$ after switching to the control perfusate. 5: records taken $50 \mathrm{~s}$ after switching to the standard perfusate. Axon $59,550 \mu \mathrm{m}$ in diameter. 
maintain the action potential duration constant for more than 5 min with the control perfutate inside the axon. When the internal solution was further switched to the test perfusate containing $\mathrm{CaCl}_{2}$ shortening or disappearance of the plateau was invariably observed (Fig. 3-3). After a few minutes, when the internal solution was switched back to the control perfusate, the plateau reappeared and grew to some extent (Fig. 3-4). Such a recovery was observed in two-thirds of the axons examined. The recovery was promoted further by switching back to the standard perfusate; after several minutes of perfusion, the amplitude and the duration of the action potential usually approached to the initial level of those before application of the test solution (Fig. 3-5).

A Ca-buffered test solution (i.e., a mixture of EDTA and Ca-glutamate) with a $\mathrm{pCa}$ of 7.6 did not show any detectable effect of the plateau duration. The lowest effective $\mathrm{Ca}^{2+}$ concentration in the range we could examine was $0.1 \mathrm{~mm}$. In some axons, $\mathrm{Ca}^{2+}$ at this concentration was enough to suppress the plateau formation almost completely, but in others it simply shortened the plateau duration. The reversibility was very good at this concentration. When the axon was perfused with $0.3 \mathrm{mM} \mathrm{Ca}^{2+}$, the plateau was abolished conspicuously as shown in Fig. 3. Perfusion with $\mathrm{Ca}^{2+}$ at concentrations higher than $0.3 \mathrm{~mm}$ caused a more rapid and complete suppression of the plateau. The reversibility was not always good at higher concentrations.

When the interior of the axon was exposed to $\mathrm{Ca}^{2+}$-containing internal perfusates, the action potential amplitude, the rate of potential rise, and the magnitude of the resting potential were reduced as shown in Fig. 4. During this membrane depolarization, the membrane resistance decreased to about $2 / 3$ of the control value (data are not shown). Spontaneous firings were sometimes observed at the initial stage of perfusion with the $\mathrm{Ca}^{2+}$-containing medium.

Intracellular $\mathrm{Ca}^{2+}$ suppressed the plateau formation effectively, but it always left a vestige of the plateau. Even at a high concentration of intracellular $\mathrm{Ca}^{2+}$, the action potential showed a hump at its falling phase (see Fig. 3-3). The duration of the action potential was always shortened by $\mathrm{Ca}^{2+}$ only to a value around $10 \mathrm{~ms}$, which was still much longer than the action potential observed in axons without TEA treatment. Thus the suppressing effect of intracellular $\mathrm{Ca}^{2+}$ on the plateau was limited; it did not nullify the effect of TEA completely.

When the plateau in TEA-treated axons has a limited duration around $10 \mathrm{~ms}$, intracellular $\mathrm{Ca}^{2+}$ did not shorten the plateau duration effectively. For example, when the internal $\mathrm{K}^{+}$concentration was $400 \mathrm{~mm}$, the plateau duration was comparatively short in the presence of the same concentration of intracellular TEA. In such a case, application of $\mathrm{Ca}^{2+}$ at a concentration as high as $5 \mathrm{~mm}$ did not influence the duration. Another example is the case in which external $\mathrm{Ca}^{2+}$ concentration was raised to $150 \mathrm{~mm}$. In this case the duration of the action potential under perfusion with the TEA solution of the usual concentration was about $10 \mathrm{~ms}$; again intracellular application of $\mathrm{Ca}^{2+}$ changed the shape and 

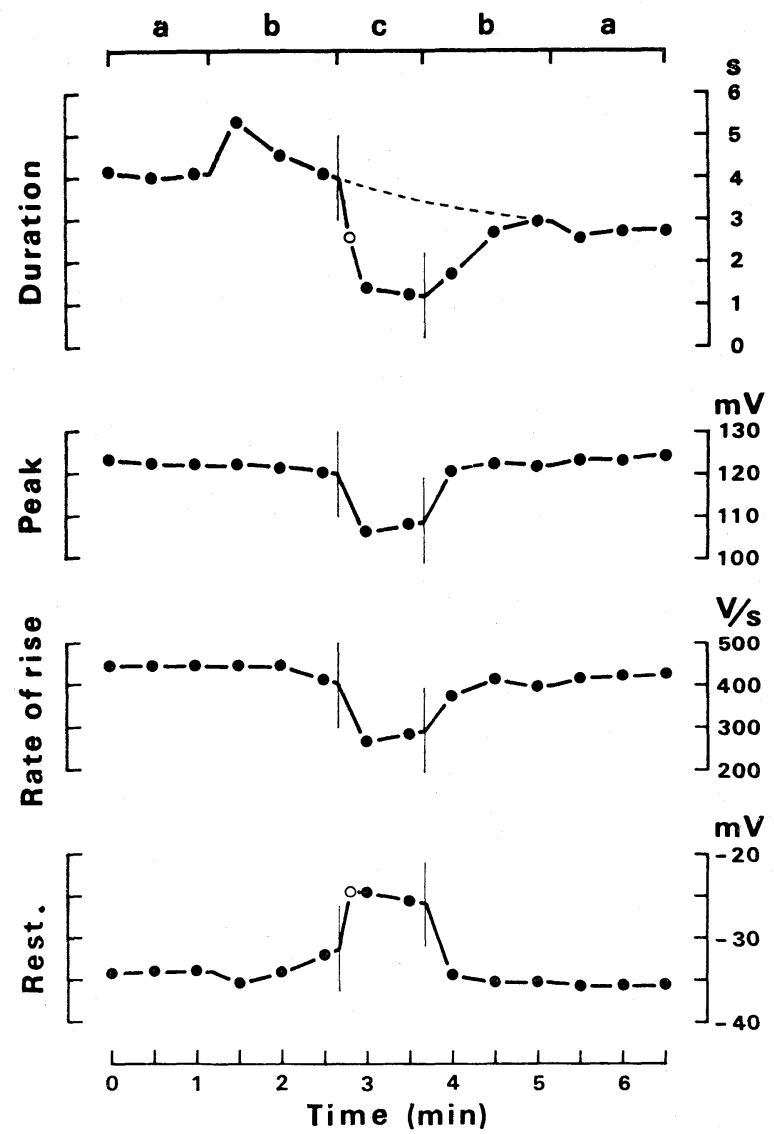

Fig. 4. Time course of electrophysiological parameters of an axon during a series of experiments to test the effect of $\mathrm{Ca}^{2+}$. Internal media were the standard perfusate during the periods a, the control perfusate during the periods $b$, and the test perfusate with $0.3 \mathrm{~mm}$ $\mathrm{Ca}^{2+}$ during the period c. Top: the duration of the action potential. Second: the amplitude at the peak of the action potential. Third: the rate of rise of the action potential. Bottom: the resting membrane potential.

the amplitude of the action potential only slightly (Fig. 5). The latter experiment indicates that the effect of intracellular $\mathrm{Ca}^{2+}$ on the plateau duration is similar to the effect of extracellular $\mathrm{Ca}^{2+}$, except that the intracellular $\mathrm{Ca}^{2+}$ was several hundred times more effective than the extracellular $\mathrm{Ca}^{2+}$.

Effects of intracellular $\mathrm{Mg}^{2+}$

Under the present experimental conditions, a high intracellular $\mathrm{Mg}^{2+}$ concentration was found to be detrimental to the maintenance of the excitability. After exposing the interior of the axon to a test solution containing $1-10 \mathrm{~mm} \mathrm{Mg}^{2+}$, 
1

A $[150 \mathrm{Ca}]_{0}$
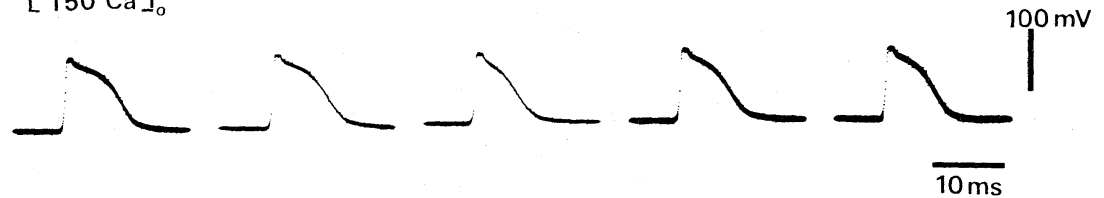

B $[52 \mathrm{Ca}]_{0}$
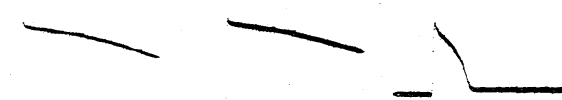
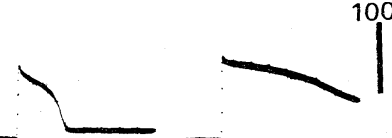

5

$$
\overline{50 \mathrm{~ms}}
$$

Fig. 5. Suppression of the effect of intracellular $\mathrm{Ca}^{2+}$ with high extracellular $\mathrm{Ca}^{2+}$. A and B are records of two series of experiments successively performed on the same axon. The external medium in A contained (in $\mathrm{mm}$ ) $375 \mathrm{NaCl}$ and $150 \mathrm{CaCl}_{2}$, with a small amount of Tris-Cl buffer. The external medium in B contained $461 \mathrm{NaCl}, 10 \mathrm{KCl}$, $52 \mathrm{CaCl}_{2}$ and $10 \mathrm{MgCl}_{2}$, with a small amount of Tris- $\mathrm{Cl}$ buffer. Internal media in 1 and 5 were the standard perfusate; in 2 and 4 the control perfusate; and in 3 the test perfusate with $0.3 \mathrm{CaCl}_{2}$ (see METHODs for the recipe). Axon $61,640 \mu \mathrm{m}$ in diameter.

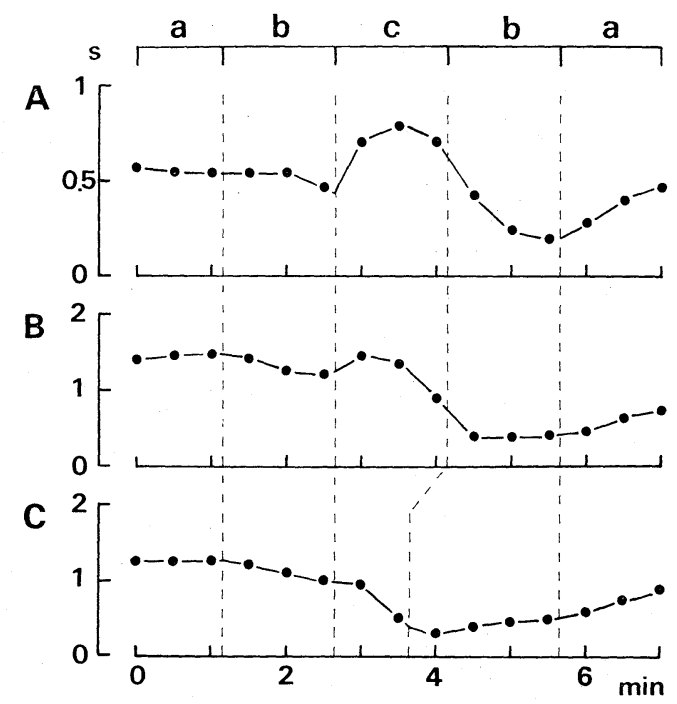

Fig. 6. Effects of $5 \mathrm{~mm} \mathrm{Mg}^{2+}$ on the plateau duration of TEA-treated axons. Plateau durations of three different axons are plotted against time. The external medium was the standard artificial sea water. Internal media in periods a were the standard perfusate; in periods $\mathrm{b}$ the control perfusate; and in periods $\mathrm{c}$ the test perfusate containing $5 \mathrm{~mm}$ $\mathrm{Mg}^{2+}$. A: axon $191,465 \mu \mathrm{m}$ in diameter. B: axon 184, $615 \mu \mathrm{m}$ in diameter. $\mathrm{C}$ : axon $182,510 \mu \mathrm{m}$ in diameter. 
9 axons out of 12 examined showed irreversible reduction in peak amplitude and plateau duration of the action potential. In these 9 axons either a simple reduction of plateau duration (Fig. 6C) or a transient prolongation followed by a reduction (Fig. 6B) was observed; in either case the reduced plateau duration did not recover after switching to the control perfusate. In the remaining 3 axons, $\mathrm{Mg}^{2+}$ definitely prolonged the plateau at this concentration range of $\mathrm{Mg}^{2+}$ (see Fig. 6A). When the test perfusate contained $5 \mathrm{mM} \mathrm{Mg}^{2}+$ the extent of prolongation was roughly $50 \%$ of the plateau duration in the control perfusate. This effect of $\mathrm{Mg}^{2+}$ was reversible. In summary, our experimental results can be explained as a summation of two opposing effects of $\mathrm{Mg}^{2+}$ : an irreversible shortening action and a reversible lengthening action. It is not clear wheather or not $\mathrm{Mg}^{2+}$ exerts any reversible shortening effect on the plateau, as $\mathrm{Ca}^{2+}$ does.

\section{Effects of intracellular $\mathrm{Sr}^{2+}$}

We examined the effects of $\mathrm{Sr}^{2+}$ on five axons. On intracellular application of $\mathrm{Sr}^{2+}$ at concentrations between $0.5-1.0 \mathrm{~mm}$, the plateau duration was invariably reduced (Fig. 7A). The effects on other properties of the axon were also similar to those of $\mathrm{Ca}^{2+}$ : the resting membrane was depolarized, the membrane resistance was decreased and the peak amplitude was reduced by $\mathrm{Sr}^{2+}$. The only significant difference was that the recovery on switching to the control perfusate was always better with $\mathrm{Sr}^{2+}$ than with $\mathrm{Ca}^{2+}$.

\section{Effects of intracellular $\mathrm{Ba}^{2+}$}

As described in METHODS, it was unnecessary to use glutamate in the control perfusate because $\mathrm{BaF}_{2}$ is soluble in water. After exposing the interior of the axon to the test perfusate which contained $\mathrm{Ba}^{2+}(0.03-1 \mathrm{mM})$, the effect of $\mathrm{Ba}^{2+}$ was found to be highly reversible. Unlike $\mathrm{Ca}^{2+}$ and $\mathrm{Sr}^{2+}, \mathrm{Ba}^{2+}$ always prolonged the plateau, as shown in Fig. 7B. The resting membrane was depolarized only slightly (2-3 $\mathrm{mV}$ with $\left.1 \mathrm{~mm} \mathrm{Ba}^{2+}\right)$. The membrane resistance has not been affected appreciably. The most conspicuous change, apart from prolongation of the plateau duration, was a marked decrease in the rate of rise of the action potential. With $0.3 \mathrm{~mm} \mathrm{Ba}^{2+}$ it decreased to a value between one-third and one-tenth of the control. The recovery was excellent when the perfusate was switched back to the control.

In one axon we used TEA-free perfusing solution in order to test whether or not $\mathrm{Ba}^{2+}$ alone can produce an action potential with a long duration. Following intracellular application of $1 \mathrm{~mm} \mathrm{Ba}{ }^{2+}$, the axon started to fire repetitively without electrical stimulation. The individual action potentials had a duration of about $15 \mathrm{~s}$. This observation indicates that $\mathrm{Ba}^{2+}$ alone can prolong the duration of action potentials.

\section{Effects of intracellular $\mathrm{Mn}^{2+}$}

$\mathrm{Mn}^{2+}$ is known to be a divalent cation with little toxic effect when applied 
A
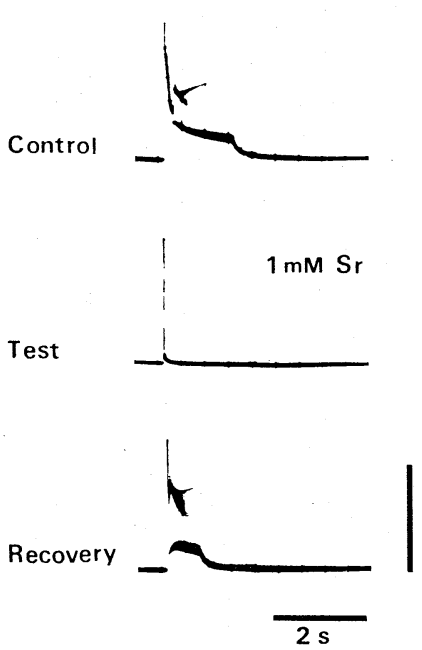

B
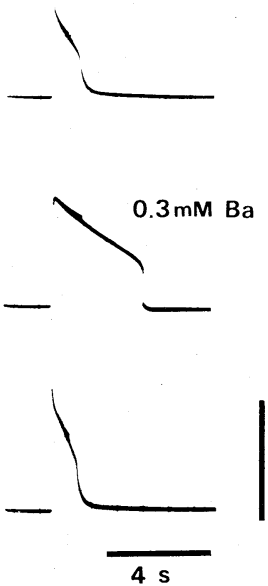

C

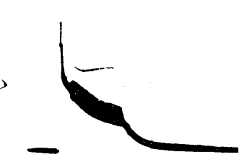

$1 \mathrm{mM} \mathrm{Mn}$

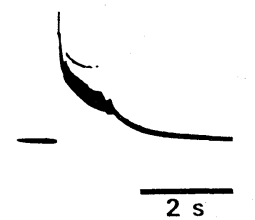

Fig. 7. Effects of intracellular $\mathrm{Sr}^{2+}, \mathrm{Ba}^{2+}$ and $\mathrm{Mn}^{2+}$ on action potentials of TEA-treated axons. External medium was always the standard artificial sea water. Internal media in top (control) and bottom (recovery) records were the same in individual axons. The vertical lines indicate $100 \mathrm{mV}$. A: axon 198, $620 \mu \mathrm{m}$ in diameter. The control perfusate contained (in $\mathrm{mm}$ ) $90 \mathrm{~K}$-glutamate, $10 \mathrm{~K}^{+}$as $\mathrm{K}$-phosphate, 5 TEA-Cl and $0.1 \mathrm{~K}$-EDTA. The test perfusate contained $1 \mathrm{SrCl}_{2}$ and all the solutes in the control perfusate except K-EDTA. B: axon $177,400 \mu \mathrm{m}$ in diameter. The control perfusate contained 0.33 $\mathrm{BaCl}_{2}$ and all the solutes in the control perfusate except K-EDTA. The peaks of the initial spikes are not well reproduced in the figures for this axon; they were $97 \mathrm{mV}$ in Control, $90 \mathrm{mV}$ in Test and $100 \mathrm{mV}$ in Recovery. C: axon $217,510 \mu \mathrm{m}$ in diameter. The control perfusate contained $100 \mathrm{KF}, 5 \mathrm{TEA}-\mathrm{Cl}$, and $2.5 \mathrm{Tris}-\mathrm{Cl}$. The test perfusate contained $1 \mathrm{MnF}_{2}$ and all the solutes in the control perfusate.

internally (BEGENISICH and LYNCH, 1974). We found that intracellular application of $\mathrm{Mn}^{2+}(0.1-5 \mathrm{mM})$ for about $10 \mathrm{~min}$ did not have serious detrimental effect on the excitability. In these experiments the control perfusate contained $100 \mathrm{~mm}$ $\mathrm{KF}$ and $5 \mathrm{~mm}$ TEA-Cl (with Tris- $\mathrm{HCl}$ buffer), and the test perfusate was prepared by adding $\mathrm{MnF}_{2}$ or $\mathrm{MnCl}_{2}$ crystals to the perfusate. As expected reversibility was good in the presence of fluoride.

$\mathrm{Mn}^{2+}$ at a concentration of $1 \mathrm{~mm}$ or higher always shortened the plateau duration (Fig. 7C). The reversibility was very good. At $0.3 \mathrm{~mm}$, the shortening effect was observed only in some axons.

With $\mathrm{Mn}^{2+}$ application, the resting potential was either unaffected or slightly $(2-3 \mathrm{mV})$ increased; the membrane resistance was either unchanged or slightly decreased; the amplitude of action potentials did not change appreciably, and the rate of rise was decreased only slightly. These changes were also highly reversible. 
Voltage clamp experiments with $\mathrm{Mn}^{2+}$

Because $\mathrm{Mn}^{2+}$ experiments could be performed with a high degree of reversibility, it was possible to measure the membrane conductance during application of $\mathrm{Mn}^{2+}$ with the use of the voltage clamp technique.

When the axon was internally perfused with the control solution containing $100 \mathrm{~mm} \mathrm{~K}^{+}$and $5 \mathrm{~mm}$ TEA, the depolarizing clamping pulse produced an initial peak current followed by a late current which lasted up to the end of the clamping pluse of about $10 \mathrm{~ms}$ (Fig. 8). The initial peak current was similar to the one obtained in an unperfused axon, but the late current was inwardly directed through the membrane in the voltage range of $20-110 \mathrm{mV}$. This late inward current is due to the existence of intracellular TEA; if TEA was eliminated from the axon interior, it was replaced by a late outward current as was described by HoDGKIN et al. (1952). The late inward current under the influence of TEA was similar to

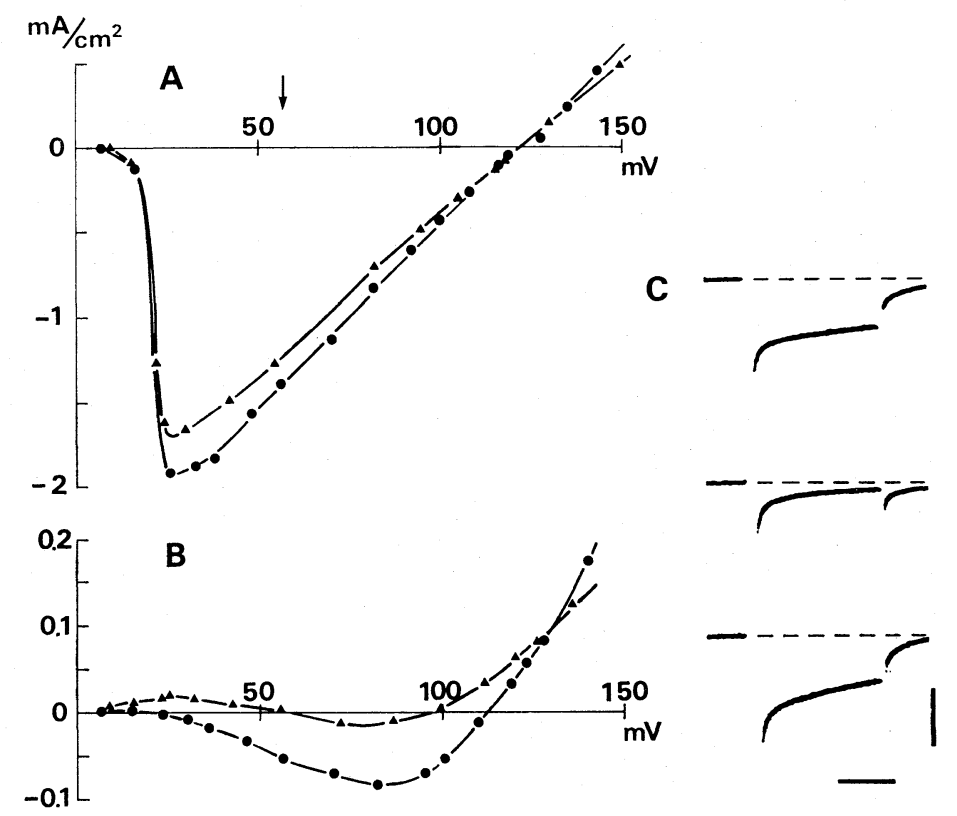

Fig. 8. Current-voltage relationship obtained by the voltage clamp technique with the clamping pulse of $11.4 \mathrm{~ms}$ duration. A: initial peak currents. B: late currents measured at the end of the clamping pulse. Circles: membrane currents with the control perfusate. Triangles: membrane currents with the perfusate containing $1 \mathrm{~mm} \mathrm{MnF}_{2}$. The holding potential was set at the initial resting potential. The arrow indicates the external potential level. The leak current measured by a $100 \mathrm{mV}$ hyperpolarizing pulse was about $0.01 \mathrm{~mA}$ / $\mathrm{cm}^{2}$. C: specimen records of the late inward current; initial currents were too large to be illustrated in these records. Top, control. Middle, with $\mathrm{Mn}^{2+}$-containing perfusate. Bottom, control again. Clamping voltages were: top, $82 \mathrm{mV}$; middle, $87 \mathrm{mV}$; bottom, $79 \mathrm{mV}$. Downward deflections represent the inward current. Calibration, $0.1 \mathrm{~mA} / \mathrm{cm}^{2}$. Time, $5 \mathrm{~ms}$. Axon $217,510 \mu \mathrm{m}$ in diameter. 
those appeared in the figures published by TASAKI and HagiWARA (1957, Fig. 11) and by ARMSTrong and Binstock (1965, Fig. 2). We observed that the late inward current disappeared on extracellular application of tetrodotoxin $\left(10^{-5} \mathrm{M}\right)$; this finding is consistent with the view that the late inward current passes through the sodium channel (ADELMAN, 1971).

When $1 \mathrm{mM} \mathrm{Mn}^{2+}$ was added to the perfusate, the initial peak current was slightly decreased, but its reversal potential did not change appreciably (Fig. 8). This is consistent with the fact that the peak amplitude and rate of rise changed very little in an unclamped axon with this perfusate. A drastic change appeared at the later phase of the clamping current (Fig. 8C). The late inward current was always profoundly inhibited, and the V-I curve obtained from values at the end of the clamping pulse came closer to the $\mathrm{V}$ axis. The slope of the curve was always small (Table 1), and the V-I curve sometimes did not cross the V axis, showing that the membrane potential was not stable in the later stage of the clamping. The late inward current reappeared when $\mathrm{Mn}^{2+}$ was removed from the axon interior; the effects of $\mathrm{Mn}^{2+}$ were highly reversible.

Table 1. Effects of intracellular $\mathrm{Mn}^{2+}$ on the late membrane conductance. ${ }^{1)}$

\begin{tabular}{|c|c|c|c|c|c|c|}
\hline \multirow{2}{*}{ Axon No. } & \multirow{2}{*}{$\begin{array}{c}\text { Concen- } \\
\text { tration } \\
\text { of } \mathrm{Mn}^{2+}(\mathrm{mM})^{2)}\end{array}$} & \multicolumn{2}{|c|}{ Conductance $\left(\mathrm{mS} / \mathrm{cm}^{2}\right)$} & \multirow{2}{*}{$\begin{array}{c}\text { Decrease } \\
(\%)\end{array}$} & \multicolumn{2}{|c|}{ Reversal potential $(\mathrm{mV})^{3)}$} \\
\hline & & Control & Test & & Control & Test \\
\hline 213 & 1 & 3.33 & 1.43 & 57 & 98 & $\mathrm{NE}^{4)}$ \\
\hline 215 & 3 & 4.55 & 2.11 & 54 & 110 & $\mathrm{NE}$ \\
\hline 216 & 1 & 7.36 & 3.84 & 48 & 109 & 103 \\
\hline 217 & 1 & 5.46 & 3.47 & 36 & 113 & 96 \\
\hline 218 & 3 & 4.38 & 1.12 & 74 & 97 & NE \\
\hline
\end{tabular}

1) Measured from the gradient of the V-I curve at the reversal potential of the control late current.

2) Intracellular concentration of $\mathrm{Mn}^{2+}$ of the test perfusate.

3) Measured from the resting level.

4) Non-existent because the curve did not cross the potential axis.

The results are clearly consistent with the observation that the plateau of an unclamped axon disappeared when $\mathrm{Mn}^{2+}$ was introduced intracellularly.

\section{DISCUSSION}

Since $\mathrm{Ca}^{2+}, \mathrm{Sr}^{2+}$ and $\mathrm{Mn}^{2+}$ shortened the plateau whereas $\mathrm{Ba}^{2+}$ and $\mathrm{Mg}^{2+}$ lengthened it, the effects of divalent cations cannot be explained as due to a single characteristic action of these cations. It is necessary to regard the action of divalent cations as a sum of at least two opposing effects. The shortening effect of $\mathrm{Ca}^{2+}, \mathrm{Sr}^{2+}$ and $\mathrm{Mn}^{2+}$ may be regarded as similar to the effect of acidic perfusates (Terakawa and Watanabe, 1976; Watanabe et al., 1977). The similarity is strengthened by our recent finding that acidic perfusates also suppress the late 
inward current (Terakawa et al., data to be published). Probably $\mathrm{Ca}^{2+}, \mathrm{Sr}^{2+}$, $\mathrm{Mn}^{2+}$ and proton act on the negative fixed charges on or near the membrane; they neutralize the charges or shield their Coulomb force. This may lead to a decrease in the membrane conductance measured by voltage clamp, resulting in shortening of the plateau duration. The similarities between effects of divalent cations and the proton on polyelectrolytes have been pointed out by MiCHAELI (1960). On the other hand, the lengthening effect of $\mathrm{Ba}^{2+}$ and $\mathrm{Mg}^{2+}$ is probably to be ascribed as due to their ion-specific, or 'lyotropic' effects which cause a saltingin of macromolecules. Unfortunately, however, the lyotropic series of cations vary according to the target macromolecules. A series which is consistent with the present results can be extracted from the literature (see, e.g., HöBER, 1945, p. 304; GUSTAVSON, 1956, p. 179). It is uncertain, however, if these results have any relevance to the phenomenon presented in this paper. A better approach seems to be to compare the protein-solubilizing power of the divalent cations on the squid axon axoplasm and to determine the sequence of these cations according to their power. This is, however, an experiment to be performed in future.

Our experimental results with $\mathrm{Ca}^{2+}$ are very similar to the shortening effect of intracellular $\mathrm{Ca}^{2+}$ on the action potential of cardiac muscle fiber (ISENBERG, 1975). In the cardiac muscle, it has been proposed that the shortening effect might be due to an activation of the potassium conductance mechanism (see MEECH, $1974 a, b)$. It is possible that the same mechanism explains the shortening of the plateau by intracellular $\mathrm{Ca}^{2+}$ in TEA-treated squid axons. For the following reasons, however, we are inclined to think that here the mechanism is different. (1) Intracellular introduction of $\mathrm{Ca}^{2+}$ caused a membrane depolarization even though the calculated potassium equilibrium potential (approximately $-58 \mathrm{mV}$ ) was larger than the resting membrane potential (around $-40 \mathrm{mV}$ ). (2) The voltage clamp experiment indicates that the intracellular introduction of $\mathrm{Mn}^{2+}$ reduces the conductance at the later period of the clamping. The shortening action of $\mathrm{Mn}^{2+}$ on the plateau can therefore be hardly explained in terms of activation of any ionic channels. If the effect of $\mathrm{Mn}^{2+}$ is assumed to be similar to that of $\mathrm{Ca}^{2+}$, it is improper to ascribe the $\mathrm{Ca}^{2+}$ effect to an activation of any ionic channels. The above reasonings are, however, still indirect.

Intracellularly applied $\mathrm{Ca}^{2+}$ shortened the duration of plateau potential of TEA-treated squid giant axons. The effect is similar to that of extracellularly applied $\mathrm{Ca}^{2+}$ (see Fig. 5), except that, with intracellular application, the necessary concentration of $\mathrm{Ca}^{2+}$ was several hundred times lower than that with extracellular application. The similarity between effects of externally and internally applied divalent cations is not confined to $\mathrm{Ca}^{2+}$. Thus externally applied $\mathrm{Ba}^{2+}$ prolongs the duration of action potentials in many excitable tissues, e.g., in the cockroach giant axon (NARAHAShI, 1961), in frog muscle fibers (SPERelakis et al., 1967), in arthropod muscle fibers (WERMAN et al., 1961; HAGIWARA and NAKA, 1964) 
and molluscan nerve cells (ECKERT and Lux, 1976). The effect is qualitatively the same with that of intracellularly applied $\mathrm{Ba}^{2+}$ described in this paper. Further, extracellularly applied $\mathrm{Mn}^{2+}$ shortens the duration of action potentials of $\mathrm{Ba}^{2+}$ treated barnacle muscle, and action potentials of the frog cardiac muscle (HAGIWARA and NAKAJIMA, 1966). Again the effect is qualitatively the same with that of intracellularly applied $\mathrm{Mn}^{2+}$ described in this paper. These results lead to a hypothesis that the primary site for some of the effects of the divalent cations is located on or near the internal surface of the membrane, and the extracellular and intracellular divalent cations produce the effects after binding the site of the plasma membrane. This hypothesis is not quite new (see, e.g., the discussion given by KASS and TSIEN, 1976), and is clearly consistent with the proposition made by TASAKI (1968) that the termination of the excited state may be a result of change in the ionic composition within and near the membrane.

We thank Dr. I. Tasaki for reading the manuscript and correcting English. This work was supported by a grant (137011) from the Ministry of Education, Science and Culture of Japan.

\section{REFERENCES}

AdeLMAN, W. J., JR. (1971) Electrical studies of internally perfused squid axons. In: Biophysics and Physiology of Excitable Membranes, ed. by Adelman, W. J., JR. Van Nostrand \& Reinhold, New York, pp. 274-319.

Armstrong, C. M. and Binstock, L. (1965) Anomalous rectification in the squid giant axon injected with tetraethylammonium chloride. J. Gen. Physiol., 48: 859-872.

BEGENISICH, T. and LYNCH, C. (1974) Effects of internal divalent cations on voltage-calmped squid axons. J. Gen. Physiol., 63: 675-689.

ECKERT, R. and Lux, H. D. (1976) A voltage-sensitive persistent calcium conductance in neuronal somata of Helix. J. Physiol., 254: 129-151.

Gustavson, K.H. (1956) The Chemistry and Reactivity of Collagen. Academic Press, New York.

HagiwarA, S. and NAKA, I. (1964) The initiation of spike potential in barnacle muscle fibers under low intracellular $\mathrm{Ca}^{++}$. J. Gen. Physiol., 48: 141-162.

Hagiwara, S. and NaKajima, S. (1966) Differences in $\mathrm{Na}$ and $\mathrm{Ca}$ spikes as examined by application of tetrodotoxin, procaine, and manganese ions. J. Gen. Physiol., 49: 793-806.

HöBER, R. (1945) Physical Chemistry of Cells and Tissues. Blakiston, Philadelphia.

Hodgkin, A. L., Huxley, A. F., and KATZ, B. (1952) Measurement of current-voltage relations in the membrane of the giant axon of Loligo. J. Physiol., 116: 424-448.

ISENBERG, G. (1975) Is potassium conductance of cardiac Purkinje fibres controlled by $\left[\mathrm{Ca}^{2+}\right]_{i}$ ? Nature, 253: 273-274.

Kass, R. S. and Tsien, R. W. (1976) Control of action potential duration by calcium ions in cardiac Purkinje fibers. J. Gen. Physiol., 67: 599-617.

KRnJEVIć, K. and Lisiewicz, A. (1972) Injections of calcium ions into spinal motoneurones. J. Physiol., 225: 363-390.

MEECH, R. W. (1972) Intracellular calcium injection causes increased potassium conductance in Aplysia nerve cells. Comp. Biochem. Physiol., 42A: 493-499.

MEECH, R. W. (1974a) Calcium influx induced a post-tetanic hyperpolarization in Aplysia neurones. Comp. Biochem. Physiol., 48A: 387-395.

MeECH, R. W. (1974b) The sensitivity of Helix aspersa neurones to injected calcium ions. 
J. Physiol., 237: 259-277.

MichaelI, I. (1960) Ion binding and the formation of insoluble polymethacrylic salts. $J$. Polymer Sci., 48: 291-299.

Moore, J. W. (1971) Voltage clamp methods. In: Biophysics and Physiology of Excitable Membranes, ed. by Adelman, W. J., JR. Van Nostrand \& Reinhold, New York, pp. 143167.

NARAHASH, T. (1961) Effect of barium ions on membrane potentials of cockroach giant axons. J. Physiol., 156: 389-414.

Sperelakis, N., Schneider, M. F., and Harris, E. J. (1967) Decreased $\mathrm{K}^{+}$conductance produced by $\mathrm{Ba}^{++}$in frog sartorius fibers. J. Gen. Physiol., 50: 1565-1583.

TASAKI, I. (1968) Nerve Excitation, a Macromolecular Approach. Thomas, Springfield.

TASAKI, I. and Hagiwara, S. (1957) Demonstration of two stable potential states in the squid giant axon under tetraethylammonium chloride. J. Gen. Physiol., 40: 859-885.

TASAKI, I., Singer, I., and TakenaKa, T. (1965) Effects of internal and external ionic environment on excitability of squid giant axon. A macromolecular approach. J. Gen. Physiol., 48: 1095-1123.

TASAKi, I., WAtanabe, A., and Lerman, L. (1967) Role of divalent cations in excitation of squid giant axons. Am. J. Physiol., 213: 1465-1474.

Terakawa, S. and Watanabe, A. (1976) Effects of intracellular pH on plateau formation following the action potential of squid giant axons. Jap. J. Physiol., 26: 693-701.

WATANABE, A. and TASAKI, I. (1972) Intracellular perfusion of squid giant axons: a study of biionic action potentials. In: Perspectives in Membrane Biophysics, ed. by AGIN, D. P. Gordon and Breach, New York, pp. 65-99.

Watanabe, A., Terakawa, S., and Nagano, M. (1977) Effects of intracellular calcium and pH on the duration of action potentials in squid giant axons. Proc. Internat. Union Physiol. Sci., XIII: 801.

Werman, R., McCANn, F. V., and GrundFest, H. (1961) Graded and all-or-none electrogenesis in arthropod muscle. I. The effects of alkali-earth cations on the neuromuscular system of Romalea microptera. J. Gen. Physiol., 44: 979-995.

YAMAGISHI, S. (1977) Effect of intracellularly perfused Ca ion on the membrane properties of squid giant axons. Proc. Internat. Union Physiol. Sci., XIII: 824. 